\title{
Compression Coating-an Approach to Colon-Specific Drug Delivery: Review
}

\author{
Sateesh Kumar V* \\ Department of Pharmaceutics, MAK College of Pharmacy, India
}

Submission: March 17, 2017; Published: June 05, 2017

*Corresponding author: Sateesh Kumar V, Department of Pharmaceutics, MAK College of Pharmacy, Moinabad, Ranga Reddy, Telangana, India, Email: vemulasatish15@gmail.com

\begin{abstract}
The present review is intended to give an update on compression coating and its applications to develop the colon-specific tablets. One of the simplest methods to gain colon-specific drug delivery is polymer coating of tablets containing active pharmaceutical ingredient. To overcome the problems related to solvent coating, pharmaceutical formulation scientists were focusing on solvent-less coating, mainly on compression coating. Compression coating is one of the promising dry coating methods that don't require either solvent or heat. Compression coating is not only applying to protect the drug from atmosphere but also to achieve the modified drug release. One of the significant areas where compression coating is widely used is site-specific drug delivery, particularly colon-specific drug delivery. Present article is mainly focusing on application of compression coating method on core tablets to deliver the dug to colon.
\end{abstract}

Keywords: Colon-Specific drug delivery; Compression Coating; Core tablets; Modified drug release; Site-Specific

\section{Introduction}

Formulation and development of site-specific drug delivery is not only to enhance the therapeutic efficacy by increasing therapeutic drug concentrations at desired site of action, but also to diminish the side effects and cost by reducing the dose and dosing frequency [1]. From the last thirty years, the pharmaceutical scientists are extensively explored in the area of colonic region for site-specific drug delivery system. Absorption and deactivation of drug in the stomach and small intestine are considered as the significant obstacles for the colonic drug release, but a well designed colon-specific drug delivery system (CDDS) can overcome the above obstacles. Targeting drugs to the colon has been turned out to be quite valuable in a variety of disorders, and the colon has been found to be a potential site for local as well as systemic administration of drugs [2]. CDDS is done mainly to treat the colonic disorders, to cure the diseases such as asthma, angina and rheumatoid arthritis those are sensitive to circadian rhythms and also to deliver the drugs like proteins, peptides and steroids [3,4]. An ideal CDDS is able to avoid the drug release in stomach and small intestine, but begins and completes the delivery in the colon.

Oral CDDS has gained increased importance from the last two decades, to treat local diseases associated with colon and for potential delivery of drugs used to treat colonic disorders $[5,6]$. Traditionally, CDDS is achieved using prod rug approach, $\mathrm{pH}-$ sensitive drug delivery, time-dependent delivery systems and microbial degradation methods using tablets, capsules, multi particulates, microspheres and liposome's [3]. Combination of any of above two approaches has greater flexibility in the design of site specific delivery to colon than single method which can result in the optimum formulation that shows no release during the initial lag period but releases the drug completely and in a sustained fashion in the colon $[7,8]$. CDDS of various drugs can be achieved by the development of coating the core tablets, either by film coating or compression coating. Among these types of tablets, compression coated tablets offer coating methodology free of solvents, which is safe and inexpensive that doesn't require special coating equipment and also offers higher stability as compared to film coating. Hence Compression coating is a simple method as compared to other methods to achieve colon delivery [8].

\section{Tablet Coating}

Pharmaceutical coatings become an important tool to formulate the desired pharmaceutical dosage forms either to achieve superior aesthetic properties (colour, texture, mouth feel and taste masking), physical and chemical protection for the drugs in cores or to achieve modified drug release characteristics. Most commonly used coating techniques in pharmaceutical industry are aqueous or organic coating, which present some 
disadvantages: time consuming, stability for heat labile and hydrolysis of degradable drug and polluted environment problem. Hence, solvent-less coatings are introduced as alternative to overcome these disadvantages. Solvent-less coatings have been categorized as compression coating, hot melt coating, supercritical fluid spray coating, electrostatic coating, dry powder coating and photo-curable coating [9]. Among these coatings, compression coating is considered as the supreme dry coating without use of solvent and heat.

\section{Compression Coating Method}

Compression coating has been introduced during the period 1950-1960 [10] to formulate incompatible drugs. Compression coating is becoming more popular and formulation scientists are showing interest to produce the modified release products owning to the advantages over solvent coating, since the process does not need the use of solvents, requires a relatively short manufacturing process and allows greater weight gain to the core tablet. Compression coating method involves the compression of coating materials around a preformed core tablet using conventional or specially designed tablet compression machine and it doesn't require use of any special solvent for coating purpose. Hence it is also known as press coating or solvent-less coating technique or dry coating technique [11]. By composition, compression coated tablet has two parts: internal core and surrounding coat. The core tablet is small porous tablet and prepared on one turret and to prepare compression coating of core tablet, another turret with a bigger die cavity is used. Compression coated tablets are prepared by putting half of the quantity of the coating material in the die cavity, then the core tablet is carefully placed in the centre of the die cavity and finally it is filled with the other half of the coating material to surround the core tablet and compress the powder, which has the core tablet inside. Getting a reproducible central positioning of the core tablet within compression coated tablet is the major limitation for this method.

\section{Advantages of Compression Coating}

A. Compression coating is considered as the absolute dry coating without use of solvent and heat.

B. Compression coating has no limitation for the cores and overcomes the adhesion problem found in spraying methods.

C. This method eliminates the time-consuming and complicated solvent coating and also improves the stability of the drug by protecting it from moisture.

D. This method has many advantages because no special coating solvent or coating equipment are needed for coating of tablet and manufacturing speed is faster [12].

E. It reduces the cost by eliminating the tedious and expensive processes of solvent disposal/treatment.

F. It can significantly reduce the processing time by eliminating drying and evaporation step and the entire process is done without any heat and thus can provide an alternative technology to coat temperature sensitive drugs [13].

G. It is considered as safe method in sense of environmental and safety issues connected with the use of organic solvents [14].

H. It is alternative method to protect hygroscopic, lightsensitive or oxygen-labile drugs from environmentalatmospheric ill effects [15].

I. It is also act alternative method to protect the acidlabile drugs form gastric fluids, proteins and peptides from intestinal fluids and also used to separate two incompatible materials (one in the core and the other in the coat).

J. It is used to mask bitter taste of drug and to protect the volatile substances.

K. This technique widely applied for drugs that require modification of drug release and to prepare multilayer tablets.

L. It requires low labor and energy than solvent coating.

\section{Limitations of Compression Coating}

A. Compression coating involves the multistep processes and multiple compressions.

B. Reproducible central positioning of the core tablet within compression coating is a major challenge for large scale industrial manufacturing.

C. In some cases, difficulties in achieving good friability values after compression coating of immediate release powder onto controlled release tablet.

D. It is difficult to coat using poor compressible polymers like guar gum and other gum materials [8].

E. For large scale industrial manufacturing of compression coated tablets, the core material should possess the ability to flow into a die during production.

\section{Applications of Compression Coating}

From the last two decades, for pharmaceutical formulation scientists, compression coating becomes a significant tool for tablet coating to develop the modified drug release tablets as well as site-specific drug delivery systems. However, compressioncoating technique has some drawbacks recently, the common manufacturing problems for compression-coated tablets, such as central positioning of the core in the compression-coated tablets and absence of core in coat, have been overcome by applying a novel one-step dry coated tablet (OSDRC) method invented by Ozeki et al. [16]. Some of the pharmaceutical aspects of compression-coated tablets in dosage form development are:

a. To protect hygroscopic, light-sensitive, oxygen labile or acid-labile drugs. 
b. To separate incompatible drugs from each other and achieve sustained release.

c. To protect the gastric mucosa from drugs like NSAIDs that cause gastric upset.

d. To modify the drug release pattern delayed and/or sustained release tables.

e. To achieve the site-specific drug delivery like colonspecific compression coated tablets.

f. To develop the pulsatile and programmable release for different drugs in one tablet and to prepare the multilayer tablets.

The present review on compression coating is mainly focused to update on the colon-specific compression coated tablets (Table 1) and some of the recent research literature is briefly explained as follows:

Maity et al. [17] were developed the prednisolone colontargeted tablets using compression coating and conducted a study to assess and correlate in vitro drug release with in vivo absorption of prednisolone The results confirmed the maximum release of drug in the colon while minimizing release in the upper gastrointestinal tract with an excellent in vitro and in vivo correlation after considering the lag time. Kavianinia et al. [18] were developed a new colon-specific compression coated tablet for delivery of ronidazole using a novel amphoteric derivative of chitosan. A combination of time, $\mathrm{pH}$, and an enzyme controlled system was used in this study and the results show that less than $2 \%$ of the drug was released in the physiological environment of the stomach and small intestine.

Maity \& Sa [19] were planned a work to develop compression-coated tablets using a blend of $\mathrm{Ca}(+2)$ ion crosslinked carboxymethyl xanthenes gum and sodium alginate for delayed release of immediate pulse release tablets of prednisolone in the colon without the need of colonic bacterial intervention for degradation of the polysaccharide coat. The core tablets were prepared by direct compression method and subsequently compression coated with different ratios of above polymers. Drug release from most of the formulations followed the Hixson-Crowell equation and sigmoid pattern as confirmed by the Waybill equation.

An attempt was made by Vemula [20] to design and formulate the ketorolac tromethamine colon-specific doublecompression coated tablets. It was planned to study the effect of double-compression coating on core mini-tablets to gain the chronopharmaceutical delivery of ketorolac tromethamine to colon. Double-compression coated tablets were prepared based on time-controlled hydroxypropyl methylcellulose K100M inner compression coat and pH-sensitive eudragit S100 outer compression coat. From the pharmacokinetic evaluation, the immediate release core mini-tablets producing peak plasma concentration at $2 \mathrm{~h}$ Tmax and colon targeted tablets showed at $12 \mathrm{~h}$ Tmax and the mean resident time was 3.68 and 10.39 $\mathrm{h}$ respectively that proves the ability of double-compression coated tablets to achieve the chronopharmaceutical delivery of ketorolac tromethamine to colon.

Patadia et al. [21] were studied the effects of hydroxypropyl methylcellulose molecular weight grades of on lag time of presscoated ethyl cellulose tablets. An immediate release prednisone core was surrounded by compression coating with variegated EC-HPMC blends. In vitro drug release testing demonstrated that the variability in lag time was increased with increase in HPMC molecular weight at studied concentration levels. Markedly, tablets with $30 \% \mathrm{w} / \mathrm{w}$ K4M in outer coat exhibited slight premature release (before the rupture of outer coat) along with high variability in lag time. Overall, the study concluded that low molecular weight HPMCs were found rather efficient than higher molecular weight HPMCs for developing robust EC-based presscoated pulsatile release formulations where precise lag time followed by sharp burst release is desired.

A significant plan is executed by Vemula [22] to study the effect of double-compression coating on flurbiprofen core minitablets to achieve the pulsatile colonic delivery. In this study, pulsatile double-compression coated tablets were prepared based on time-controlled hydroxypropyl methylcellulose K100M inner compression coat and pH-sensitive eudragit S100 outer compression coat. In vitro drug release studies and in vivo pharmacokinetic studies proved the pulsatile colonic release of flurbiprofen. The best formulation retarded the drug release in stomach and small intestine ( $3.42 \pm 0.12 \%$ in $5 \mathrm{~h}$ ) and progressively released to colon $(99.78 \pm 0.74 \%$ in $24 \mathrm{~h})$ and produced the peak plasma concentration (Cmax) was $14677.51 \pm 12.16 \mathrm{ng} / \mathrm{ml}$ at $3 \mathrm{~h}$ Tmax and $10.61 \mathrm{~h}$ mean resident time.

A study designed by Vemula \& Katkum [23] is intended to formulate and study the pharmacokinetics of colon-specific pulsatile ketorolac tromethamine tablets using doublecompression coating method. In this, inner compression coat made of sodium starch glycolate as swelling layer and outer compression coat (release controlling layer) contains sodium alginate and hydroxypropyl methylcellulose K $15 \mathrm{M}$ to gain the colon-specific drug release.

Vemula \& Bontha [24] were developed the flurbiprofen colon targeted compression coated tablets using guar gum based on microbial degradation approach. Direct compression method was used to prepare the flurbiprofen core tablets and they were compression coated with guar gum. Then the tablets were optimized with the support of in vitro dissolution studies and further it was proved by pharmacokinetic studies. Formulation of guar gum compression coated tablets was considered as a suitable method to give colon-specific release of flurbiprofen without loss in upper gastrointestinal tract.

Sharma et al. [25] were formulated the time-dependent and $\mathrm{pH}$ sensitive press-coated tablets for colon specific drug delivery of naproxen. The core tablets were prepared by wet granulation 
method then press coated with hydroxypropyl cellulose or Eudragit RSPO: RLPO mixture and further coated with Eudragit S-100 by dip immerse method. The SEM of tablets suggested that the number of pores got increased in $\mathrm{pH} 7.4$ medium followed by dissolution of coating layer. The tablets coat erosion study suggested that the lag time depends upon the coating concentrations of polymers. A time-dependent hydrophilic polymer and $\mathrm{pH}$ sensitive polymer based press-coated tablets of naproxen were promising delivery for colon targeting.

Vemula \& Veerareddy [26] were developed ketorolac tromethamine time dependent colon targeted compression coated tablets using hydroxypropyl methylcellulose by direct compression method. The formulation is optimized based on the in vitro drug release studies and further evaluated by x-ray imaging technique and in vivo pharmacokinetic studies in healthy humans to ensure the colonic delivery. The results of the in vivo study in human volunteers showed that the colon-specific tablets didn't release the drug in stomach and small intestine, but delivered it to the colon.

The study developed by Veerareddy \& Vemula [27] was aimed to develop a new pulsatile colonic drug delivery system using combined approaches of a time and $\mathrm{pH}$ dependent approaches. Hydroxypropyl methylcellulose K4M-eudragit S100 compression coated tablets of flurbiprofen were capable of protecting the drug from being released in the upper region of GI system, but delivered to the colon resulting in a slow absorption of the drug and making it available for local action in colon when compared to immediate release tablets based on in vitro drug release studies and in vivo pharmacokinetics.

Rujivipat \& Bodmeier [28] were developed the pH-erosioncontrolled compression-coated tablets for potential colonic drug delivery based on compression-coatings of eudragit L100-55 and ethylcellulose [29-31]. Tablet cores containing model drugs of varying solubilities were compression-coated with different ratios of above polymers and evaluated for drug release, and all drugs were released in a pulsatile fashion in higher $\mathrm{pH}$-media after a lag time. The addition of ethylcellulose avoided premature drug release in lower $\mathrm{pH}$ media and significantly increased the lag time in higher $\mathrm{pH}$ media because of a reduction in wettability, media uptake and erosion of the compression-coatings. Tablets compression-coated with blends of eudragit and ethylcellulose resulted in excellent release properties for potential targeting to the lower intestinal tract with no release in lower $\mathrm{pH}$-media and rapid release after a controllable lag time in higher $\mathrm{pH}$ media [32].

\section{Conclusion}

The present review was an attempt made to give update on compression coating and its applications. It gave information and importance of compression coating and elaborated the recent research on colon-specific compression coated tablets of various combinations of drug and polymers that delivers the drug successfully to colon without loss in the stomach and small intestine.

\section{References}

1. Krishnaiah YSR, Satyanarayana S, Prasad YVR, Rao SN (1998) Evaluation of guar gum as a compression coat for drug targeting to colon. Int J Pharm 171: 137-146.

2. Libo Y, James SC, Joseph AF (2002) Colon specific drug delivery; new approaches and in vitro/in vivo evaluation. Int J Pharm 235(1-2): 1-15.

3. Vemula SK, Veerareddy PR (2009) Different approaches to design and evaluation of colon specific drug delivery systems. Int J Pharm Tech 1(1): 1-35.

4. Asghar LFA, Chandran S (2006) Multiparticulates formulation approach to colon-specific drug delivery: Cur perspectives. J Pharm Sci 9(3): 327-338.

5. Maroni A, Zema L, Curto MDD, Foppoli A, Gazzaniga A, et al. (2012) Oral colon delivery of insulin with the aid of functional adjuvants. Adv Drug Del Rev 64(6): 540-556.

6. Vincent HL, Suman KM, Swarbick J, Boylan CJ (2002) Drug deliveryoral colon-specific Encyclopedia of pharmaceutical technology. Marcel Dekker: New York, USA, pp. 871-885.

7. Asghar LF, Chure CB, Chandran S (2009) Colon specific delivery of indomethacin: effect of incorporating ph sensitive polymers in xanthan gum matrix bases. AAPS Pharm Sci Tech 10(2): 418-429.

8. Veerareddy PR, Vemula SK (2012) Formulation, evaluation and pharmacokinetics of colon targeted pulsatile system of flurbiprofen. J Drug Targ 20(8): 703-714.

9. Bose S, Bogner RH (2007) Solventless pharmaceutical coating processes: a review. Pharm Dev Tech 12(2): 115-131.

10. Winheuser J, Cooper J (1956) The pharmaceutics of coating tablets by compression. J Am Pharm Assoc 45(8): 542-545.

11. Hardik L, Hiren B, Chandrababu M, Modasiya K (2011) Review on Solventless Coating Technology. Am J PharmTech Res 1(4): 154-175.

12. Swati C, Jagdale MS, Sali AL, Barhate JN, Loharkar AR (2010) Design and evaluation of enteric press coated tablet for pulsatile delivery of atenolol. Int J Pharm World Res 1(2): 1-15.

13. Cole G, Hogan J, Aulton M (1995) Pharmaceutical coating technology. Taylor and Francis: London, 1-5.

14. Zhu J, Zhang H (2005) Ultra fine powder coatings: An innovation. Powder Coat 6: 39-47.

15. Janugade BU, Patil SS, Patil SV, Lade PD (2009) Formulation and evaluation of press-coated montelukast sodium tablets for pulsatile drug delivery system. Int J Chemtech Res 1(3): 690-695.

16. Ozeki Y, Watanabe Y, Inoue S, Danjo K (2003) Comparison of the compression characteristics between new one-step dry-coated tablets (OSDRC) and dry-coated tablets (DC). Int J Pharm 259(1-2): 69-77.

17. Maity S, Kundu A, Karmakar S, Sa B (2016) In vitro and in vivo correlation of colon-targeted compression-coated tablets. J Pharm (Cairo) 2016: 5742967.

18. Kavianinia I, Plieger PG, Cave NJ, Gopakumar G, Dunowska M, et al. (2016) Design and evaluation of a novel chitosan-based system for colon-specific drug delivery. Int J Biol Macromol 85: 539-546.

19. Maity S, Sa B (2016) Compression-Coated Tablet for Colon Targeting: Impact of Coating and Core Materials on Drug Release. AAPS PharmSciTech 17(2): 504-515. 
20. Vemula SK (2015) Formulation and pharmacokinetics of colon-specific double-compression coated mini-tablets: Chronopharmaceutical delivery of ketorolac tromethamine. Int J Pharm 491(1-2): 35-41.

21. Patadia R, Vora C, Mittal K, Mashru R (2015) Investigating effects of hydroxypropyl methylcellulose (HPMC) molecular weight grades on lag time of press-coated ethylcellulose tablets. Pharm Dev Tech 21(7): 794-802.

22. Vemula SK (2015) A novel approach to flurbiprofen pulsatile colonic release: Formulation and pharmacokinetics of double-compression coated mini-tablets. AAPS Pham Sci Tech 16(6): 1465-1473.

23. Vemula SK, Katkum R (2015) Colon-specific double-compression coated pulsatile tablets of ketorolac tromethamine: Formulation development and pharmacokinetics. J Drug Del Sci Tech 29: 78-83.

24. Vemula SK and Bontha VK (2013) Colon targeted gaur gm compression coated tablets of flurbiprofen: Formulation, development and pharmacokinetics. Bio Med Res Int 2013: 1-8.

25. Sharma P1, Chawla A, Pawar P (2013) Design, development, and optimization of polymeric based-colonic drug delivery system of naproxen. Sci World J 1: 654829.

26. Vemula SK, Veerareddy PR (2013) Development, evaluation and pharmacokinetics of time-dependent ketorolac tromethamine tablets. Expert Opin Drug Del 10(1): 33-45.

27. Vemula SK, Veerareddy PR, Devadasu VR (2012) Pharmacokinetics of colon-specific $\mathrm{pH}$ and time-dependent flurbiprofen tablets. Eur J Drug Met Pharmacokinet 40(3): 301-311.
28. Rujivipat S, Bodmeier R (2010) Improved drug delivery to the lower intestinal tract with tablets compression-coated with enteric/ nonenteric polymer powder blends. Eur J Pharm Biopharm 76(3): 486-492.

29. Vemula SK, Veerareddy PR, Devadasu VR (2015) Pharmacokinetics of colon-specific $\mathrm{pH}$ and time-dependent flurbiprofen tablets. Eur J Drug Met Pharmacokinet 40(3): 301-311.

30. Vemula SK, Veerareddy PR, Devadasu VR (2014) Pharmacokinetics of ketorolac tromethamine compression-coated tablets for colon delivery. Drug Del Trans Res 4(4): 310-319.

31. Vemula SK, Katkum R (2015) Formulation, Development and pharmacokinetics of ketorolac tromethamine colon targeted guar gum compression coated tablets. Anal Chem Let 5(3): 149-161.

32. Hashem FM, Shaker DS, Nasr M, Saad IE, Ragaey R, et al (2011) Guar gum and hydroxy propyl methylcellulose compressed coated tablets for colonic drug delivery: in vitro and in vivo evaluation in healthy human volunteers. Drug Discov Ther 5(2): 90-95.

33. Chickpetty SM, Baswaraj R, Nanjwade BK (2010) Studies on development of novel combined time and $\mathrm{pH}$ dependent solvent-less compression coated delivery systems for colonic delivery of diclofenac sodium. Asian J Pharm Clin Res 3(2): 110-113. 